Research Article

\title{
Experimental Study of the Engineering Mechanical Properties of the Foundation Soil for Offshore Wind Power Platforms
}

\author{
Yi Fang $\mathbb{D}^{1,2}$ Yuejun Lv, ${ }^{1}$ XingYuan Zhou, ${ }^{1}$ and Yanju Peng $\mathbb{D}^{1}$ \\ ${ }^{1}$ National Institute of Natural Hazards, Ministry of Emergency Management of China, Beijing, China \\ ${ }^{2}$ Key Laboratory of Crustal Dynamics, China Earthquake Administration, Beijing, China \\ Correspondence should be addressed to Yanju Peng; pengyj408@126.com
}

Received 22 May 2021; Revised 13 September 2021; Accepted 27 September 2021; Published 14 October 2021

Academic Editor: Piguang Wang

Copyright ( $\odot 2021$ Yi Fang et al. This is an open access article distributed under the Creative Commons Attribution License, which permits unrestricted use, distribution, and reproduction in any medium, provided the original work is properly cited.

\begin{abstract}
Most of the coastal beach zone in the world is rich in wind energy reserves and has great potential for offshore wind power development. However, the sedimentary environment in the coastal area is complex and changeable, and the nature of the foundation soil of offshore wind power platforms is weak and complex, which is quite different from that in the land areas. In order to systematically study the mechanical properties of marine foundation soils, a series of geotechnical tests are carried out on representative undisturbed seabed soils, such as basic laboratory geotechnical tests, bender element tests, undrained triaxial shear tests, and resonance column tests. The test results show that shear wave velocity $\left(V_{s}\right)$ of marine silt and silty clay increases linearly with the buried depth; the stress-strain relationship curves of silty clay and silt present two different modes of development: strain hardening and strain softening, the undrained shear strength $\left(S_{\mathrm{d}}\right)$ of the two types of marine soils decreases with the increase of the void ratio (e), and both present a good single correlation. Based on the relationship between $S_{\mathrm{d}}$ and $V_{\mathrm{s}}$ from the laboratory test of disturbed seabed soils, an undrained strength evaluation method of undisturbed seabed soils under the current stratum conditions incorporating in situ shear wave velocity is established. The dynamic shear modulus $(G)$ in the various strain ranges of undisturbed silty clay and silt increases regularly with the buried depth $(H)$. Meanwhile, the maximum dynamic shear modulus $\left(G_{\max }\right)$ linearly increases with the increase of $H$, whereas the attenuation relationship of $G$ decreases with the increase of $H$. The prediction method of $G$ based on buried depth is established with high accuracy.
\end{abstract}

\section{Introduction}

Wind energy is currently one of the fastest-growing renewable energy sources with the most promising industrial prospects. Worldwide, onshore wind power started earlier. A large number of wind farms have been built successively, in America, Germany, China, etc. In the past decade, offshore wind farms have gradually become the popular development direction of the global wind power industry. The main reason for this development tendency is that electricity consumption of the coastal areas has increased year by year, and offshore wind power has a large single-unit generating capacity; moreover, the wind energy resources are more stable and abundant. In order to satisfy the demand for offshore wind power transmission and improve the structure and reliability of the structure of urban power grids, the number of wind power platform projects which will be constructed is increasing annually around the world. The offshore environmental loads and geological conditions are more complex than their onshore counterparts so that it is more difficult to build offshore wind power platforms than onshore's. In particular, the foundation soil of the proposed offshore wind power platform is deep, weak, and complex, and these problems could be exacerbated by construction disturbances. Therefore, it is indispensable to carry out a systematic investigation of the engineering mechanical properties of the seabed soil of the foundation of the proposed offshore wind power platforms.

Compared with onshore drilling expense, the cost of offshore drilling is rather higher; moreover, the soil samples are more difficult to obtain, few experimental research has been carried out, and in return, it has caused a serious lag in 
basic research on the dynamic characteristics of the seabed soil. Koutsoftas and Fischer [1] found that the stress history has a strong influence on the dynamic shear modulus $G$, and the modulus value of overconsolidated clay is larger than that of normally consolidated clay. The standardized modulus ratio for the undrained shear strength $\mathrm{Su}$ is mainly affected by the type, strain level, and overconsolidation ratio OCR of soils. The influence of stress history on the damping ratio is not significant. Bryan and Stoll [2] conducted resonance column tests on sand, clay, and silt taken from the sea about 5 miles from the coast of New Jersey, USA, and found that $G_{\max }$ is mainly related to the void ratio and $\sigma_{m}$. Yamamoto et al. [3] found that $G_{\max }$ of marine sediments is proportional to $\left(\sigma_{\mathrm{m}}\right)^{0.5}$. Kagawa [4] discovered that the $G_{\max }$ of marine soft clay decreases with the increase of void ratio (e) and plasticity index (Ip) and is proportional to the average effective confining pressure $\left(\sigma_{m}\right)$, which is basically consistent with the test results of two marine clays by Koutsoftas [1]. Vrettos and Savidis [5] conducted resonance column tests on 4 undisturbed clays at 2 sites on the west coast of Greece and found that $G_{\max }$ for low plastic clay is proportional to $\left(\sigma_{\mathrm{m}}\right)^{0.5}$, and high plastic clay is proportional to $\left(\sigma_{m}\right)^{0.5}$, and the influence of the plasticity index of cohesive soil should be taken into consideration to predict $G_{\text {max }}$. The plasticity index and the average effective confining pressure have a strong influence on the dynamic characteristics of the offshore cohesive soil. Lanzo et al. [6] conducted an experimental study on the undisturbed soft clay in the Adriatic Sea in Italy. The results showed that when the relative consolidation ratio and $e$ are close to each other, the effective confining pressure affects the $G_{\max }$ of marine clay significantly. And the decay curve of the dynamic shear modulus ratio $G / G_{\max }-y$ of marine soil is close to that of the terrestrial soil. Kong et al. [7] studied the basic properties of marine soil from the Qiongzhou Strait of China. The test found that marine soil has unique physical properties, and it was classified as silt based on the soil quality. However, its compression deformation characteristics and strength indicators are different from those of general silt or silty soil, and its shear strength is relatively higher, whereas it has certain structural strength. Zhang et al. [8] found that the fast-deposited silty soil has a high consolidation rate under its own weight. After the normal consolidation is completed, the strength continues increasing with time, and there is a nonuniform consolidation phenomenon and a pseudooverconsolidation state similar to those of the primary soil that occurred with the increase of the depth. Liu et al. [9] analyzed the advantages and disadvantages of the existing offshore wind turbine foundations. In order to modify the weakness of the existing offshore wind turbine foundations, they proposed a new umbrella-type suction anchor foundation suitable for offshore wind power platforms in the Yellow River Delta, and its structural advantages and installation method were explained. Wu et al. [10] presented an experimental investigation which was conducted through comprehensive bender element tests on $G_{\max }$ of marine silty sand. The results indicate that, under otherwise similar conditions, $G_{\max }$ decreases with the decrease of $e$ or fines content (FC) but decreases with the increase of FC. Zhao et al. [11] presented an elastoplastic modeling method for dynamic consolidation of the liquefiable seabed around a pipeline subjected to ocean environmental loadings. Zhang et al. [12] proposed a transient seismic structure-watersediment-rock interactional model to evaluate the seismic response of the marine structure in ocean space under obliquely incident earthquakes. Wang et al. [13] presented a substructure method for seismic responses of offshore wind turbines considering nonlinear pile-soil dynamic interaction.

The above researches show that no systematically experimental researches on the mechanical properties of general marine engineering have been carried out yet. Consequently, we carried out this article which is based on the offshore wind power platform project that is ongoing in the Yellow Sea of China. The representative undisturbed seabed soil was collected from the site to be conducted with basic laboratory geotechnical tests, including bender element tests, undrained triaxial shear tests, and resonance column tests to determine the physical and mechanical properties of the silt and silty clay. The correlations between the basic physical indicators, the undrained shear strength, and the shear wave velocity of the primary marine soil are investigated. Eventually, an undrained shear strength evaluation method is proposed, and a predictive model of dynamic shear modulus and depth is presented. This research can provide basic scientific data for the design and construction of offshore wind power platforms.

\section{Samples and Resonant Column Test}

\subsection{Stratigraphic Information and Basic Physical Properties.} To study the engineering mechanical properties of typical marine foundation soil of offshore wind power platforms, exploration works have been carried out in the waters offshore of the Yellow Sea of China, and representative boreholes were selected. Undisturbed silty clay and silt were collected from multiple depths within the boreholes using open thin-walled soil samplers. The soils were sampled within a depth range of 2 to $70 \mathrm{~m}$, and sulfate sandstone was encountered below $73 \mathrm{~m}$. The natural water content, specific gravity, natural density, void ratio, and plasticity index of the samples were tested in accordance with the ASTM standards. Table 1 presents the soil depths, the corresponding physical and mechanical property indices of the undisturbed silty clay, and silt samples from the seabed to the bedrock. As can be seen from the table, the silty clay layer and the silt layer each accounted for approximately half of the total core length, and they are discontinuously distributed. The upper layer had a relatively large water content, and the water content remained at approximately $30 \%$ at soil depths of greater than $14 \mathrm{~m}$. The specific gravity ranged from 2.66 to 2.70 , exhibiting only a small difference. The plasticity index of the silty clay was greater than 10, and the plasticity index of the silt was less than 10. Based on the comprehensive consideration of the drilling exploration data, the site engineering geological survey, and the geophysical prospecting data, the strata of the site can be divided into five major layers. The lithological characteristics of the soil layers from top to bottom are as follows. 
TABLE 1: Basic physical properties of undisturbed soil.

\begin{tabular}{|c|c|c|c|c|c|c|}
\hline Depth $(H)(\mathrm{m})$ & Lithology & Water contents $(w)(\%)$ & Specific gravity $\left(G_{s}\right)$ & Density $(\rho)\left(\mathrm{g} \times \mathrm{cm}^{-3}\right)$ & Void ratio $(e)$ & Plasticity index $\left(I_{p}\right)$ \\
\hline $2.1-2.3$ & Silty clay & 33.7 & 2.69 & 1.89 & 0.90 & 15.16 \\
\hline $3.6-3.8$ & Silty clay & 38.9 & 2.70 & 1.78 & 0.87 & 14.55 \\
\hline $10.4-10.6$ & Silty clay & 36.2 & 2.69 & 1.84 & 0.99 & 12.54 \\
\hline $11.9-12.1$ & Silt & 49.7 & 2.67 & 1.61 & 1.48 & 9.25 \\
\hline $13.4-13.6$ & Silty clay & 34.1 & 2.69 & 1.90 & 0.90 & 15.13 \\
\hline $13.8-14.0$ & Silt & 41.5 & 2.68 & 1.73 & 1.19 & 9.56 \\
\hline $17.2-17.4$ & Silty clay & 28.6 & 2.70 & 1.87 & 0.82 & 15.21 \\
\hline $20.6-20.8$ & Silt & 30.5 & 2.66 & 1.82 & 0.98 & 9.74 \\
\hline $25.7-25.9$ & Silt & 30.0 & 2.66 & 1.78 & 0.94 & 7.68 \\
\hline $30.8-31.0$ & Silt & 34.2 & 2.66 & 1.88 & 0.90 & 8.69 \\
\hline $34.3-34.5$ & Silty clay & 29.6 & 2.70 & 1.90 & 0.78 & 15.81 \\
\hline $35.7-35.9$ & Silty clay & 32.2 & 2.68 & 1.92 & 0.76 & 17.39 \\
\hline $37.7-37.9$ & Silt & 28.6 & 2.69 & 1.89 & 0.83 & 8.82 \\
\hline $39.1-39.3$ & Silt & 28.6 & 2.67 & 1.91 & 0.80 & 9.15 \\
\hline $39.5-39.7$ & Silt & 28.8 & 2.68 & 1.88 & 0.93 & 9.15 \\
\hline $42.7-42.9$ & Silt & 28.2 & 2.68 & 1.84 & 0.87 & 8.70 \\
\hline $43.1-43.3$ & Silt & 27.2 & 2.66 & 1.90 & 0.78 & 7.44 \\
\hline $44.1-44.3$ & Silt & 28.6 & 2.67 & 2.04 & 0.68 & 8.25 \\
\hline $45.5-45.7$ & Silt & 30.4 & 2.68 & 1.88 & 0.86 & 9.83 \\
\hline $48.5-48.7$ & Silty clay & 30.2 & 2.69 & 1.91 & 0.83 & 11.59 \\
\hline $54.9-55.1$ & Silty clay & 31.8 & 2.68 & 1.93 & 0.83 & 11.10 \\
\hline $59.8-60.0$ & Silty clay & 29.9 & 2.68 & 2.01 & 0.81 & 12.14 \\
\hline $69.6-69.8$ & Silty clay & 27.5 & 2.68 & 1.90 & 0.80 & 14.26 \\
\hline
\end{tabular}

Layer I was dominated by very soft, bluish-gray, plastic silty clay. The soil samples had high water contents and were basically saturated, and the layer was approximately $17.5 \mathrm{~m}$ thick.

Layer II was dominated by dense, light grayish-yellow silt. The soil samples had high water contents and were basically saturated, and the layer was approximately $13.5 \mathrm{~m}$ thick.

Layer III was dominated by medium-density, grayishyellow silt. The soil samples had high water contents and were basically saturated, and the layer was approximately $5 \mathrm{~m}$ thick with a thin ( 2.5 m thick) intercalated silt layer.

Layer IV was dominated by medium-soft, bluish-gray, plastic silty clay. The soil samples had high water contents and were close to saturation, and the layer was more than $28 \mathrm{~m}$ thick. Layer $\mathrm{V}$ was sulfate sandstone.

2.2. Testing Equipment. As shown in Figure 1, the undrained shear tests and shear wave velocity tests were carried out using a GCTS HCA-300 cyclic loading tester (USA) and a bender element system at the National Institute of Natural Hazards, Ministry of Emergency Management of China. The confining pressure and back pressure of the HCA-300 were loaded and measured at up to $1 \mathrm{MPa}$ using a standard pressure/volume controller. The axial force can be independently controlled for static and dynamic loading, with a maximum of $10 \mathrm{kN}$ and a frequency of $5 \mathrm{~Hz}$. All of the sensors had a test accuracy of greater than $0.1 \%$ of the full scale. The soil shear wave velocity was tested using the bender elements installed at the top and bottom of the HCA-300 pressure chamber.

As shown in Figure 2, the modulus and damping tests were conducted using a GCTS TSH-100 high-precision fixed-free resonant column test system at the out using a
GCTS HCA-300 cyclic loading tester (USA) and a bender element system at the National Institute of Natural Hazards, Ministry of Emergency Management of China. The strain response curve of soil was recorded at $0.2 \mathrm{~ms}$ intervals using an eight-channel digital acquisition system, with an accuracy of $10^{-6}$ for the parameters, i.e., soil resonance frequency, maximum shear strain, shear wave velocity, and shear modulus.

2.3. Testing Method. The standard sample accommodated by the GCTS HCA-300 cyclic loading tester is $50 \times 100 \mathrm{~mm}$ in size, but the field drilled sample was approximately $100 \times 200 \mathrm{~mm}$ in size. Therefore, it was necessary to manufacture the primary soil sample into a standard sample with a diameter of $50 \mathrm{~mm}$ and a height of $100 \mathrm{~mm}$. After the standard-sized samples were obtained, they were saturated using the vacuum saturation method in accordance with the ASTM standards. In addition, to avoid the impact of the differences between the prepared samples on the test results, the samples were each saturated in a saturation tank for 10 hours.

The undrained shear tests and the shear wave velocity tests were carried out as follows. After a saturated sample was mounted on the base of the bender element, with its top connected to the top of the bender element and the displacement sensor, the pressure chamber was tightly sealed. Next, the soil sample was uniformly consolidated under a natural stress state according to the depth of the primary soil sample. First, the consolidated samples were subjected to a nondestructive bender element shear wave velocity test, followed by undrained and drained shear tests, with a constant shear rate of $0.1 \% / \mathrm{min}$. The modulus and damping tests were carried out as follows. The sample was mounted 


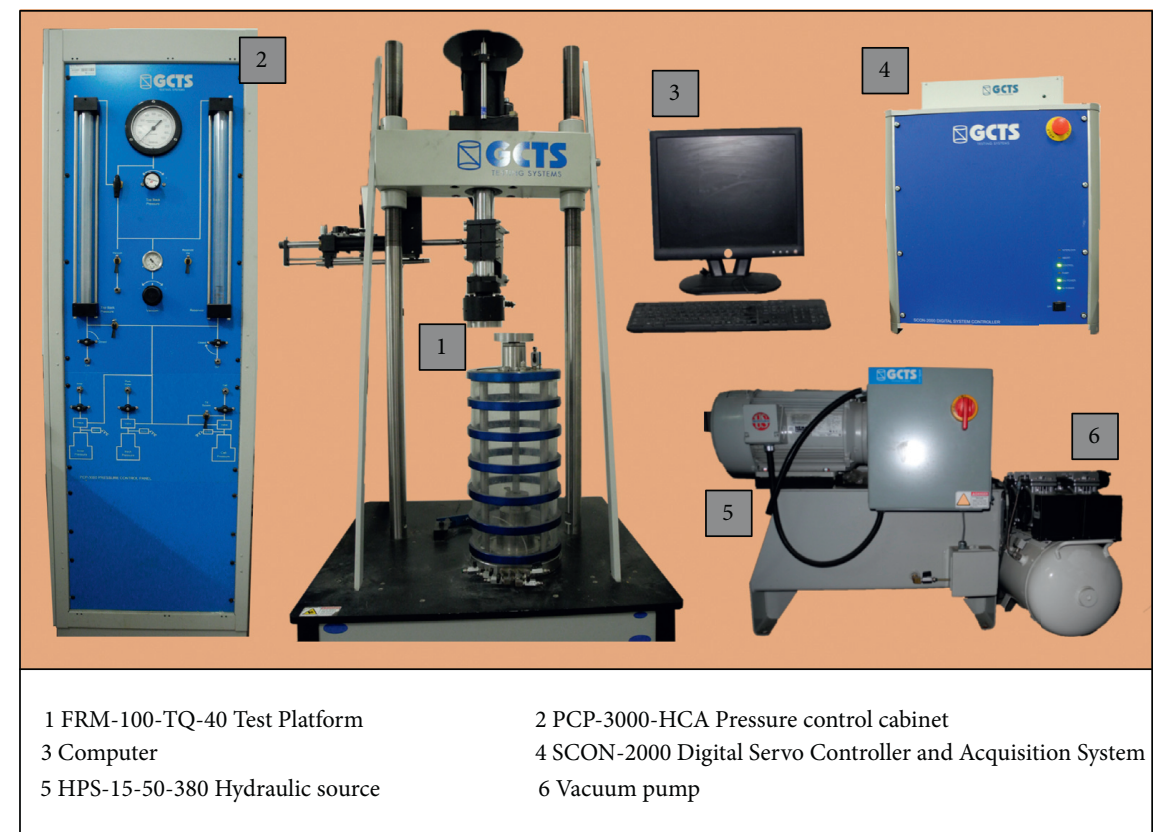

Figure 1: GCTS HCA-300 dynamic hollow cylinder apparatus and bender element system.

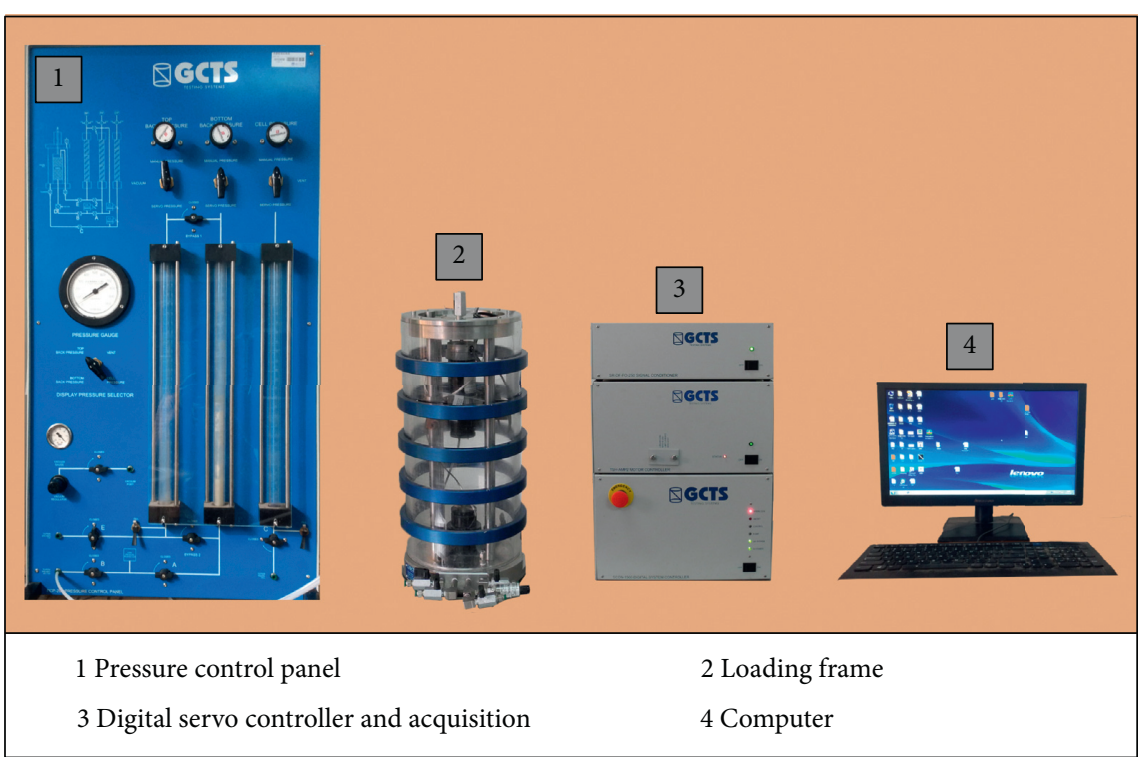

FIGURE 2: GCTS TSH-100 type resonant column testing system.

on the base of the instrument, with its top connected to the suspension torsion driving device and the displacement sensor, the axial displacement data were set to zero, and the pressure chamber was sealed. Then, the soil sample was uniformly consolidated under a natural stress state according to the depth of the primary soil sample. The top of the consolidated sample was excited using the automatic suspension torsion device controlled by the WIN-CATSSTD program. After the sweep frequency reached the resonance frequency, the soil sample underwent free vibration. Based on the soil's strain response curve, which was recorded by the eight-channel digital acquisition system, the program automatically calculated the test values, such as the dynamic shear strain $\gamma$, the dynamic shear modulus $G$, and the damping ratio $\lambda$. The excitation frequency was increased in steps, and Step 4 was repeated until the shear strain amplitude of the sample was greater than $5 \times 10^{-4}$, at which point the test was completed.

\section{Test Results and Analysis}

3.1. Variation Law of Shear Wave Velocity and $e$ and $H$ of Undisturbed Soil. In the bender element test, $V_{s}$ was determined using the following equation: 


$$
V_{s}=\frac{d}{t}
$$

where $d$ is the distance from the transmitting section to the receiving section of the bender element chip. Bai et al. [14] showed that when comparing methods of determining waveform of $t$, the time domain first arrival method is simpler and more accurate than the frequency domain method. Therefore, in the shear wave velocity tests, a single sinusoidal pulse wave was selected as the excitation signal, the excitation frequency was determined based on the specific stress and the soil density, and the time domain first arrival method was used to determine $t$. A single sinusoidal pulse of 1 to $40 \mathrm{kHz}$ was applied to the sandy soil as the excitation signal. It was found that a clear, effective signal was received at the receiving end of the bender element at an excitation frequency of $10 \mathrm{~Hz}$, which is consistent with the test results of Yang and Liu [15]. Figure 3 shows a typical received bender element signal diagram for a sample. Points $A, B$, and $C$ in the figure are the first deflection point, the first peak point, and the first arrival point of the received bender element signal, respectively. The propagation time $t$ of the shear wave was determined by taking point $C$ as the time of the first arrival of the shear wave.

Figure 4 shows the relationship between the shear wave velocity $V_{\mathrm{s}}$ and the void ratio $e$ of the primary marine soil. As can be seen from the figure, for the same $e, V_{\mathrm{s}}$ of the silt is significantly greater than that of the silty clay. $V_{\mathrm{s}}$ of the silt decreases linearly with the increase of $e$ whereas $V_{\mathrm{s}}$ of silty clay tends to decrease with the increase of $e$, but there is no obvious correlation. The correlation between $V_{\mathrm{s}}$ and $e$ shows that for low-plasticity undisturbed seabed silt, $e$ can be used to characterize the particle composition of the soil and the effect of the consolidation stress on the soil's density. Therefore, $e$ is an effective physical index that can be used to evaluate the soil shear wave velocity. Unlike that of silt, $e$ of silty clay cannot be used as a single index for the evaluation of the shear wave velocity. This is because silty clay has high plasticity, and thus, characterizing its particle composition using only the void ratio fails to consider the effect of the cohesion between the soil particles on the mechanical properties of the soil. Figure 5 shows the relationship between the shear wave velocity $V_{\mathrm{s}}$ and soil depth $H$ of the primary seabed soil. $V_{\mathrm{s}}$ values of both the silt and silty clay increase linearly with increasing $H$. The degree of influence of $H$ on $V_{s}$ of marine silt is apparently greater than that on $V_{s}$ of silty clay. In summary, an equation for evaluating $V_{s}$ of undisturbed seabed soil based on the soil depth can be established as follows:

$$
V_{s}=a \cdot H+b,
$$

where $a$ and $b$ are fitting parameters. $a$ reflects the degree of influence of $H$ on $V_{\mathrm{s}}$ of the primary seabed soil and $b$ is the $V_{\mathrm{s}}$ of the primary seabed soil corresponding to the state with no initial consolidation stress. For silty clay, $a=4.3, b=69.4$, and the coefficient of determination $R^{2}=0.99$; as for silt, $a=1.9, b=112.8$, and $R^{2}=0.98$.

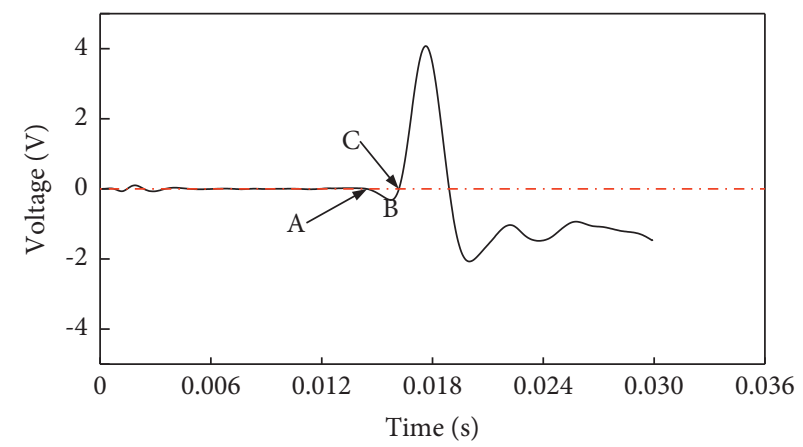

FIgURE 3: Time history of output voltage from the receiver of the bender element testing system.

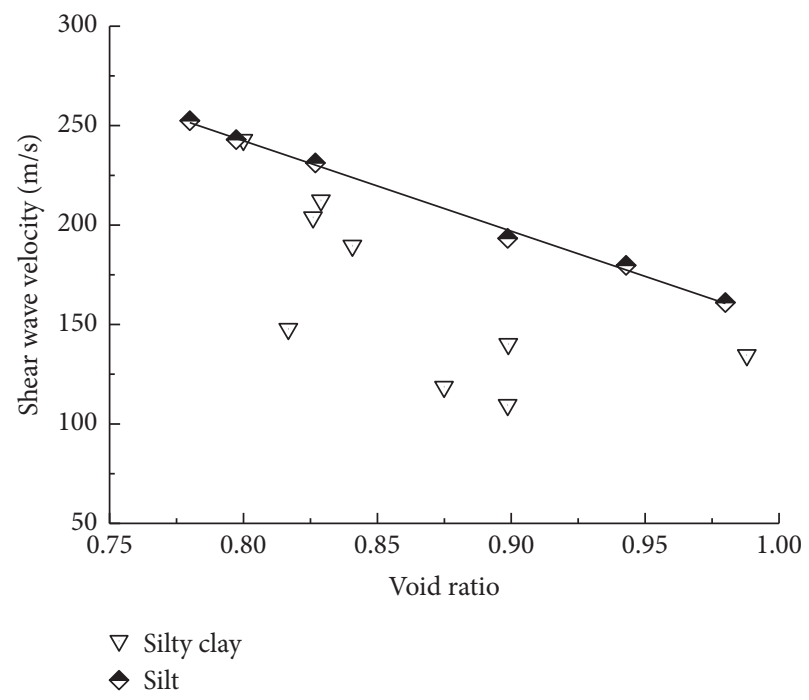

FIGURE 4: Relationship between shear wave velocity $V_{s}$ and void ratio $(e)$ of undisturbed marine soil.

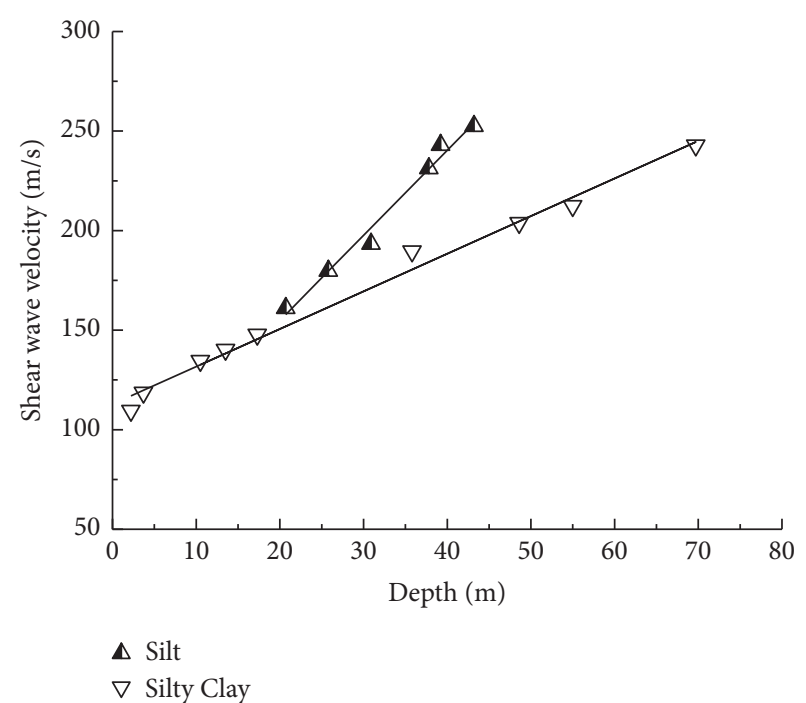

FIGURE 5: Relationship between shear wave velocity $V_{s}$ and depth $(H)$ of undisturbed marine soil. 
3.2. Stress-Strain Relationship of Undisturbed Soil. Figure 6 shows that the curves depict the relationship between the deviatoric stress $\sigma_{d}$ and the axial strain $\varepsilon$ of the undisturbed marine silty clay and silt. The stress-strain relationship curves of the silty clay and silt both exhibit two different development modes: strain hardening and strain softening. For example, when the value of $e$ is large, the stress-strain relationship is characterized by strain hardening; that is, as $\varepsilon$ of the sample increases, the pore water pressure increases, and $\sigma_{d}$ gradually increases at a rate that gradually decreases with increasing $\varepsilon$ and gradually tends to 0 , at which point the sample reaches a critical state. When the value of $e$ is small, the stress-strain relationship is characterized by strain softening; that is, as $\varepsilon$ increases, $\sigma_{d}$ initially increases rapidly, and then, after reaching the peak deviatoric stress, it decreases rapidly until at a rate that decreases with the increase of axial strain and gradually tends to 0 , at which point the sample also approaches a critical state. During this process, the sample volume exhibits a significant expansion trend, and the pore water pressure decreases. It should be pointed out that when $e$ of silty clay is less than 0.84 , the stress-strain relationship readily transforms from strain hardening to strain-softening; whereas the silt sample does not exhibit strain-softening until $e$ reaches 0.8 . Therefore, compared with that of silty clay, the stress-strain relationship of silt requires a higher density to transition from strain hardening to strainsoftening.

\subsection{Undrained Shear Strength Characteristics of Undisturbed} Soil. The triaxial undrained shear strength $S_{d}=\sigma_{d} / 2$ (the peak value of the stress-strain curve is taken as $S_{d}$ when there is a peak in the stress-strain curve; otherwise, the asymptotic value of the deviatoric stress at $15 \%$ of the axial strain is taken as $S_{d}$ ) is an important parameter that characterizes the strength properties of soil. The undrained shear strength of the primary soil obtained from the laboratory element tests was obtained after the soil sample was unloaded and reconsolidated in the laboratory, and it differs from the Coulomb shear strength. Soil samples obtained at different depths may correspond to different positions on the unloading rebound curve or on the normal compression curve. Therefore, the determination of the undrained shear strength index of the primary soil is affected by complexity factors. The depth can be used to characterize the effective stress that the soil is subjected to in its natural state, and it can reflect the mechanical properties of the soil to some extent. Figure 7 shows the variations in the undrained shear strengths of the silty clay and silt with depth. As can be seen from the figure, the overall $S_{d}$ values of both the silty clay and the silt increase as the depth of the soil layer increases, but there is no clear single correlation, which indicates that the depth or the corresponding consolidation stress is an important factor affecting $S_{d}$, but it is not the only factor.

Figure 8 shows the variation in the undrained shear strength $S_{d}$ of the silty clay and silt with increasing void ratio $e$. As can be seen from the figure, the $S_{d}$ values of the silty clay and silt both decrease linearly with increasing $e$. It should be pointed out that the rate of decrease of $S_{d}$ of the silty clay with increasing $e$ is significantly higher than that of the silt, indicating that the undrained shear characteristics of the silty clay are more sensitive to soil density. Compared with $H$, e can more reasonably characterize $S_{d}$ of the soil. This is because $e$ can characterize the soil's structural state under the natural effective stress conditions to some extent. Figure 8 also demonstrates that $e$ can reflect the stress-strain development of the primary soil. In summary, $e$ can be used as a reasonable and effective index for evaluating the undrained shear strength of the primary soil:

$$
S_{d}=A \cdot e^{B}
$$

where $A$ and $B$ are fitting parameters. For the silty clay, $A=9.45, B=-8.3$, and $R^{2}=0.89$. For the silt, $A=135.9$, $B=-3.2$, and $R^{2}=0.80$.

Figure 9 shows the relationship between the undrained shear strength $S_{d}$ and the shear wave velocity $V_{s}$ of the primary marine soil. As can be seen from the figure, $S_{d}$ increases with increasing $V_{s}$, and with the exception of individual silty clay samples, there is a correlation between $S_{d}$ and $V_{s}$ for the other disturbed primary soils. Therefore, the relationship between $S_{d}$ and $V_{s}$ can be established based on laboratory element tests conducted on disturbed primary soils, and combined with the existing correction methods for the mechanical parameters of disturbed and undisturbed soils, the method for evaluating the undrained strength properties of the undisturbed primary soil under the current formation conditions was established based on the field shear wave velocity results. This will facilitate the establishment of a preliminary method for predicting the foundation soil strength of offshore wind power platforms, which will decrease testing costs significantly. It should be noted that the undrained shear strength evaluation method based on shear wave velocity is relatively accurate for low-plasticity soils, but it may underestimate the shear strengths of high-plasticity soils. To obtain the undrained shear strengths of high-plasticity soils more accurately, it is necessary to carry out more accurate undrained shear tests considering the basic physical properties of the soil.

3.4. Variation in $G$ with Soil Depth. Figures 10(a) and 10(b) show the variations in the dynamic shear modulus $G$ of the undisturbed silty clay and silt at different depths within the same borehole with increasing shear strain $\gamma$. The following can be seen from the figure. The $G$ values of the silty clay and silt at different depths all decrease with increasing $\gamma$. For very small strains $\left(\gamma<10^{-5}\right)$, the $G$ values of the silty clay and silt basically remain stable. As $\gamma$ increases $\left(\gamma>10^{-5}\right)$, the $G$ values of the silty clay and silt begin to decrease rapidly. In addition, a comparison of Figures 10 (a) and 10(b) reveals that, at the same strain level, the $G$ values of both the silty clay and the silt increase with increasing soil depth $H$, and the increase in $G$ with increasing $H$ for the silt is significantly greater than that for the silty clay. Therefore, $G$ of the primary soils within each strain range is mainly determined by the soil type and soil depth $H$, and there may be a pattern in the variation in $G$ with $H$ for the same type of primary soil within different strain ranges. 


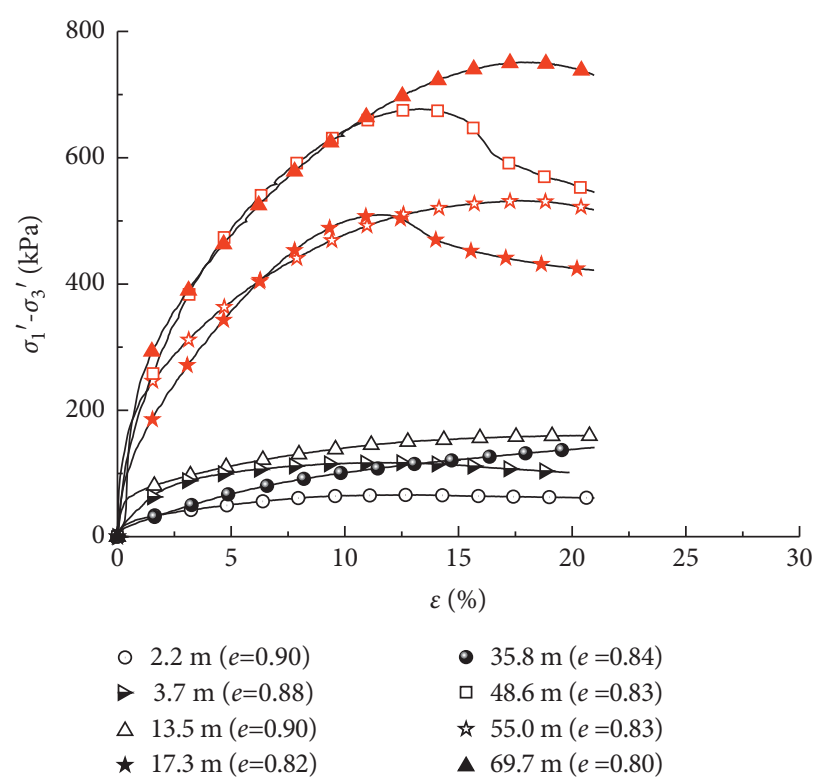

(a)

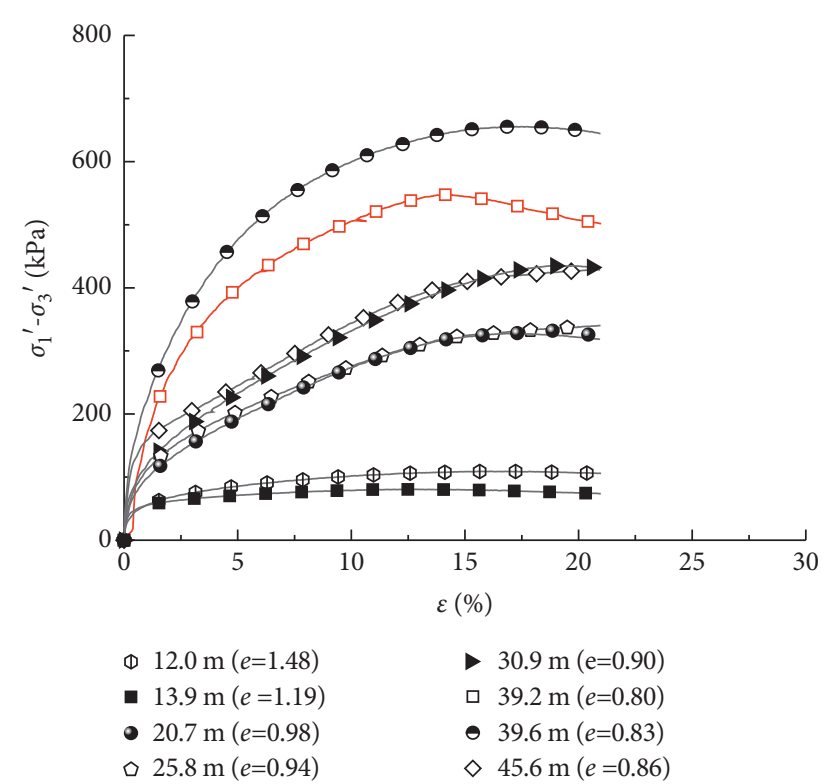

(b)

FIgURE 6: Stress-strain relationship curve of undisturbed marine soil. (a) Slit clay. (b) Slit.

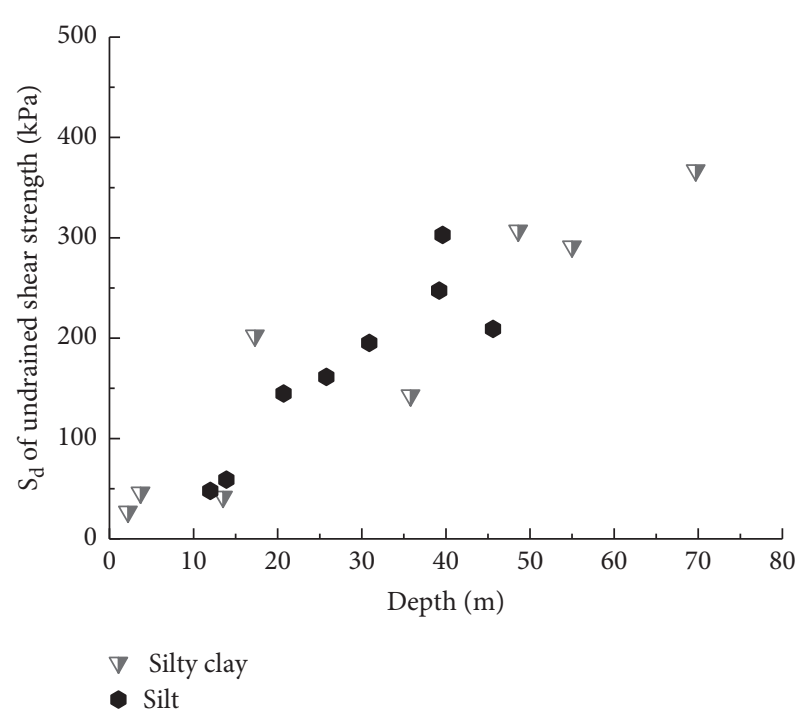

Figure 7: Relationship between undrained shear strength $S_{d}$ and depth $(H)$ of undisturbed marine soil.

3.5. Variation in $G_{\max }$ with Soil Depth. As an important parameter for evaluating the dynamic properties and characterizing the maximum elastic stiffness of a kind of soil, the maximum dynamic shear modulus $G_{\max }$ is usually defined as $G$ when $\gamma \leq 10^{-6}$. Based on the hyperbolic relationship between the soil's dynamic modulus and dynamic strain under small-amplitude vibration, which was proposed by Hardin and Drnevich [16], a linear relationship between $1 / G$ and $\gamma$ can be obtained (i.e., $1 / G=a+b \gamma$ ), and then, $G_{\max }$ of the silty clay and the silt can be obtained at different depths.

Figure 11 shows the $G_{\max }$ values of the silty clay and silt at different depths and the curves demonstrating the

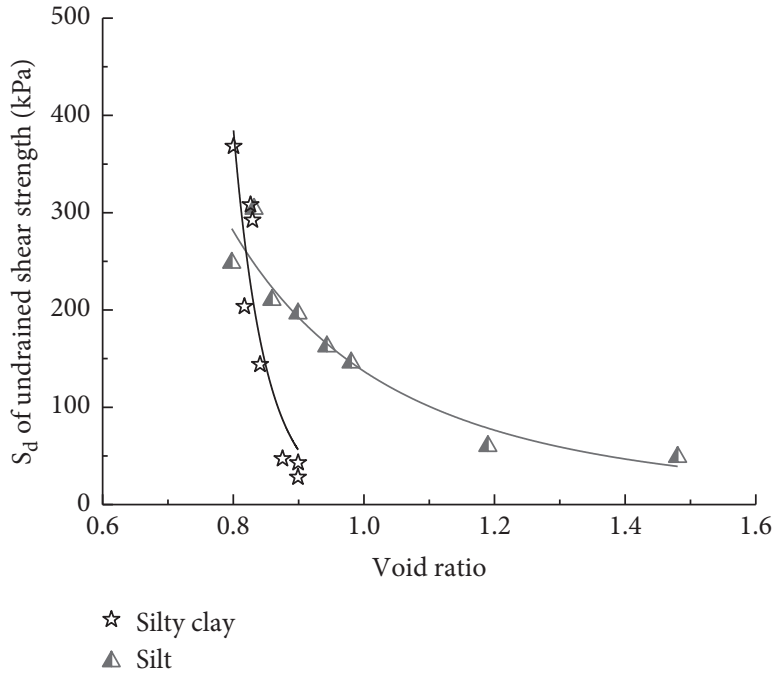

FIGURE 8: Relationship between undrained shear strength $S_{d}$ and void ratio $(e)$ of undisturbed marine soil.

relationship between $G_{\max }$ and soil depth $H$. As can be seen from the figure, the $G_{\max }$ values of the silty clay and silt both increase linearly with increasing $H$, but the increase rate of $G_{\max }$ with $H$ is much higher for silt than for silty clay. Based on this, an empirical equation for determining the $G_{\max }$ values of different types of primary soils based on $H$ (or effective stress $\sigma_{m}^{\prime}$ ) can be established as follows:

$$
G_{\max }=A+n \times 0.1 P_{a} \times\left(\frac{\sigma_{m}^{\prime}}{P_{a}}\right),
$$

where $A$ and $n$ are fitting parameters, and their specific values are given in Table $2 . \sigma_{m}^{\prime} / \mathrm{Pa}$ characterizes the soil depth $H$. 


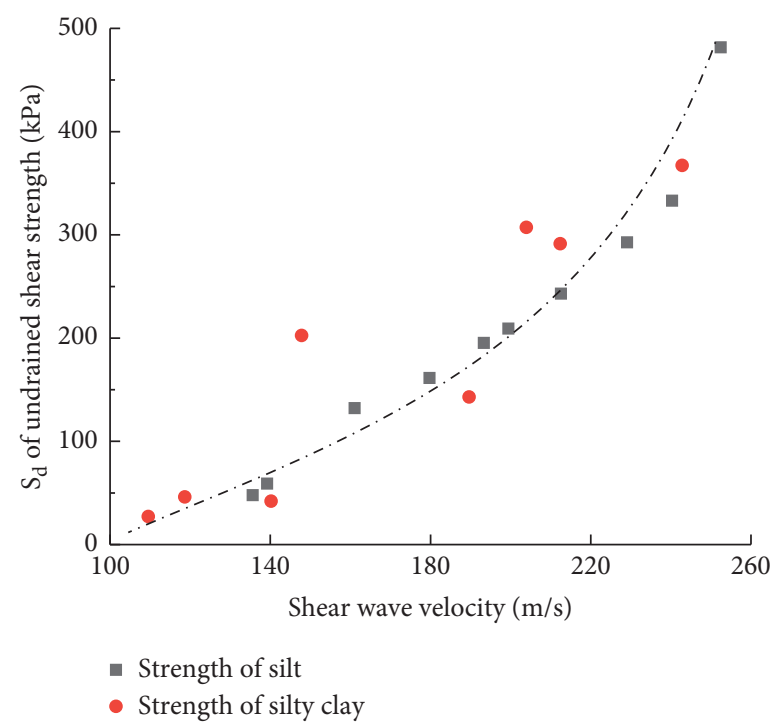

FIGURE 9: Relationship between undrained shear strength $S_{d}$ and shear wave velocity $V_{s}$ of undisturbed marine soil.

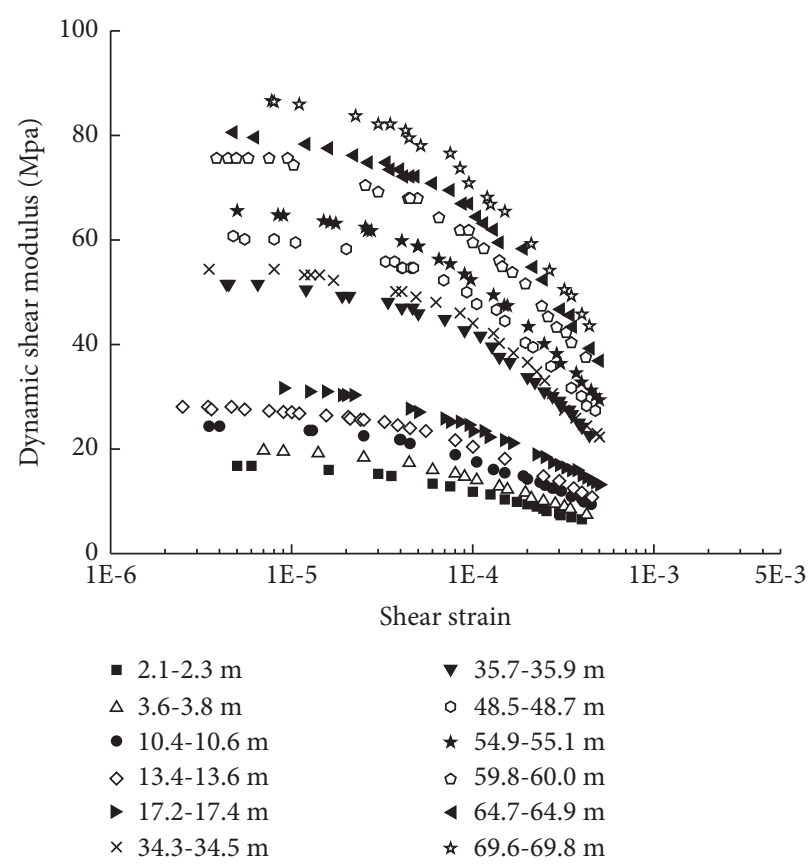

(a)

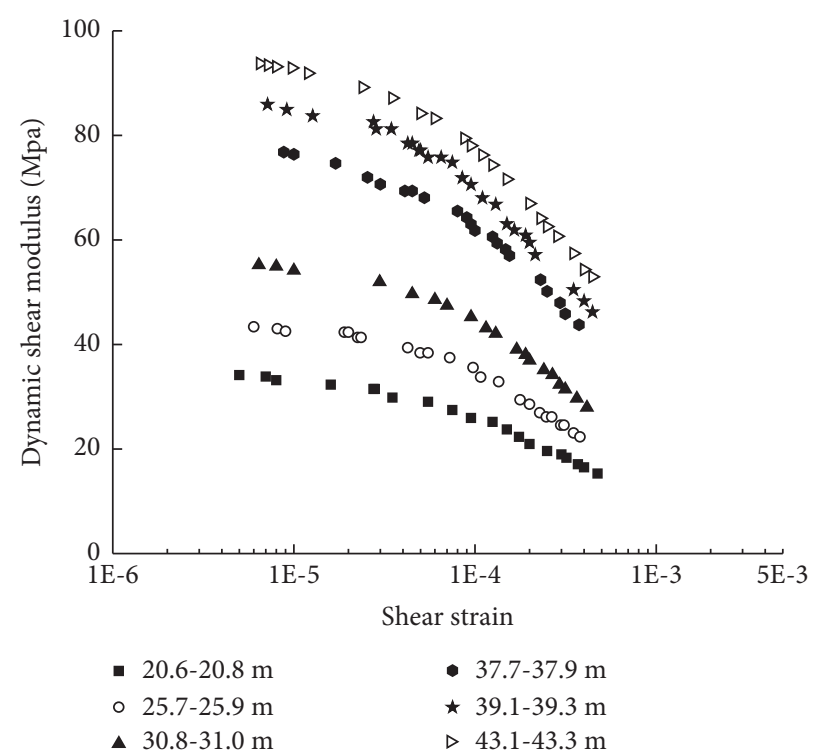

(b)

FIGURE 10: Relationship between dynamic shear modulus $(G)$ and shear strain $\gamma$ of each undisturbed soil in the same borehole. (a) Silty clay and (b) silt.

3.6. Comparison of $G_{\max }$ Obtained by Different Test Methods. As mentioned above, $G_{\max }$ is an important parameter to characterize soil dynamics. This paper uses bending element and resonance column tests to obtain $G_{\max }$, which can prompt us to better explore the dynamic characteristics of seabed soil.

Figure 12 shows the comparison of the two test results. It can be seen from the figure that the result of the bending element test is generally greater than the result of the resonance column test. There is a certain linear relationship between the two, which also verifies the reliability of the two tests in this paper.
3.7. Variation in the Dynamic Shear Modulus Ratio $\left(G / G_{\max }\right)$ with Soil Depth. The variation of $G / G_{\max }$ against $\gamma$ directly reflects the nonlinear of the stress-strain relationship of soils under dynamic loads [17]. To investigate the variations in the decay characteristics of the $G$ values of the silty clay and silt with increasing $\gamma$ at different $H$, the normalized dynamic shear modulus $G$, i.e., $G / G_{\max }$, was used to examine the silty clay and silt at different depths. In view of the location of the borehole near the Yellow Sea and the nature of the soft soil, which has a water content close to that of seabed soft soil, the three-parameter Martin-Davidenkov model was selected to 


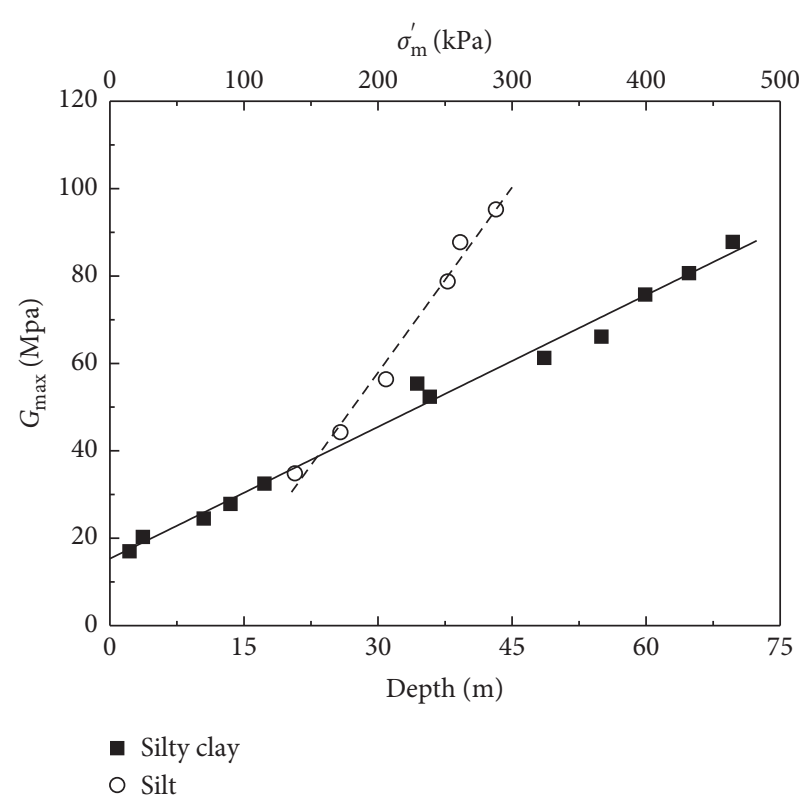

Figure 11: Variation law of $G_{\max }$ with soil depth $(H)$ (effective confining pressure $\sigma_{m}^{\prime}$ ) of silty clay and silt.

TABle 2: Parameters $A$ and $n$ and the decision coefficients $R^{2}$ in the $G_{\text {max }}$ prediction formula.

\begin{tabular}{lccc}
\hline Lithology & $A$ & $n$ & $R^{2}$ \\
\hline Silty clay & 15.29 & 1.51 & 0.989 \\
Silt & -26.8 & 4.23 & 0.981 \\
\hline
\end{tabular}

fit the resonant column test data for the silty clay and silt at different depths in the borehole from the surface to the bedrock [18]. The $G / G_{\max }$ is defined as [16]

$$
\frac{G}{G_{\max }}=1-\left[\frac{\left(\gamma / \gamma_{0}\right)^{2 \beta}}{1+\left(\gamma / \gamma_{0}\right)^{2 \beta}}\right]^{\alpha}
$$

where $\alpha, \beta$, and $\gamma_{0}$ are all fitting parameters. When $\alpha=1$ and $\beta=0.5$, the model simplifies to the H-D hyperbolic model [16], in which $\gamma_{0}$ is a reference shear strain with a clear physical meaning, and its value is defined as the shear strain amplitude when $G / G_{\max }=0.5$ [19].

The curves illustrating the variation in $G / G_{\max }$ with increasing $\gamma$ for the silty clay and silt at different depths are shown in Figure 13. As can be seen from the figure, the relationship between the normalized shear modulus $G / G_{\max }$ and $\gamma$ for the silty clay and silt at different depths exhibits strong nonlinear characteristics. That is, when $\gamma<10^{-5}$, the $G / G_{\max }$ values of the silty clay and silt do not decrease significantly with increasing $\gamma$; but when $\gamma>10^{-5}$, as $\gamma$ increases, the $G / G_{\max }$ values of the silty clay and silt begin to rapidly decrease and tend to 0 . It should be noted that for the same strain level, the $G / G_{\max }$ values of both the silty clay and silt increase with increasing soil depth $(H)$, which is accompanied by a decrease in the decay gradient. Furthermore, the overall $G / G_{\max }-\gamma$ curve varies from low to high; that is, the small-strain dynamic properties of the soil gradually change from nonlinear to linear.

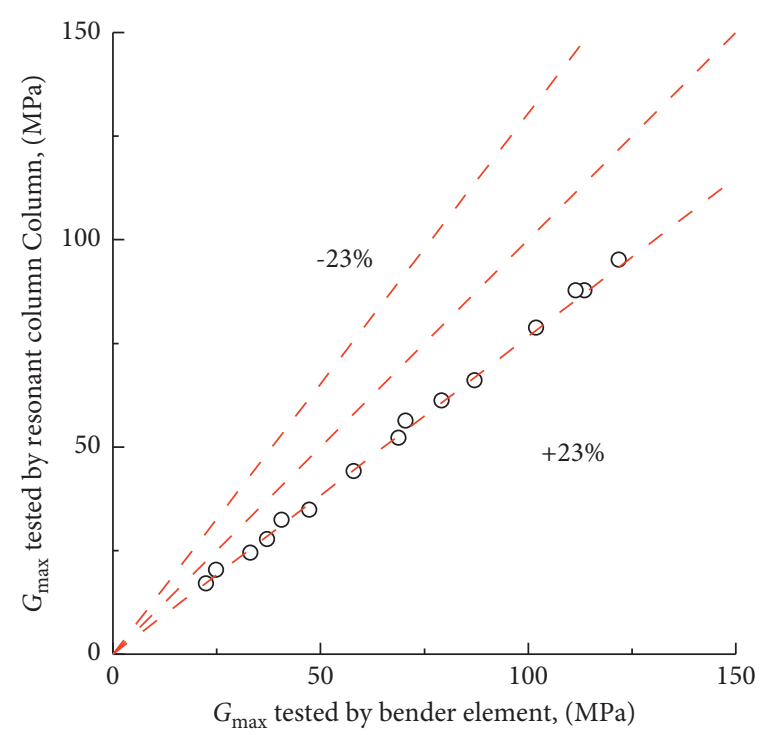

Figure 12: Comparison of Gmax obtained by different test methods.

To obtain the specific variation pattern of the decay characteristics of $G$ of the primary soil with $H$ over the full strain range, the variations in the fitting parameters $\alpha, \beta$, and $\gamma_{0}$ of the silty clay and silt with depth $H$ were comparatively analyzed. $\alpha$ and $\beta$ are close to 1 and 0.5 , respectively, for the undisturbed silty clay at different depths; and they are close to 1 and 0.42 , respectively, for the undisturbed silt at different depths, indicating that soil depth has no significant effect on fitting parameters $\alpha$ and $\beta$ of the primary soils.

Figure 14 shows the $\gamma_{0}$ values of the silty clay and silt at different depths and the variation in $\gamma_{0}$ with soil depth $H$. For the silty clay and silt, $\gamma_{0}$ increases linearly with increasing $H$, but the rate of increase of $\gamma_{0}$ with $H$ for the silt is much greater than that for the silty clay, which is consistent with the variation pattern of the $G / G_{\max }-\gamma$ curve with $H$ for the silty clay and silt (Figure 11). Based on the variations in $\gamma_{0}$ with $H$ for the silty clay and silt, an empirical relationship between $\gamma_{0}$ and $H$ was established for the silty clay and silt as follows:

$$
\gamma_{0}(\%)=B+C \times\left(\frac{\sigma_{m}^{\prime}}{P_{a}}\right)
$$

where $B$ and $C$ are fitting parameters.

In summary, the Martin-Davidenkov model can be further simplified by taking into account the variation in the parameters $\alpha, \beta$, and $\gamma_{0}$ with $H$ in order to empirically describe the decay of the $G / G_{\max }$ values of the silty clay and silt at different depths.

$$
\frac{G}{G_{\max }}=\frac{1}{1+\left(\gamma / \gamma_{0}\right)^{2 \beta}},
$$

where the parameters $\alpha$ and $\beta$ are their average values of 1 and 0.5 , respectively, for the silty clay and 1 and 0.42 , respectively, for the silt. Table 3 gives the recommended values of $\alpha, \beta$, and $\gamma_{0}$ for the simplified decay models of the $G / G_{\max }$ values of the silty clay and silt at different depths. 


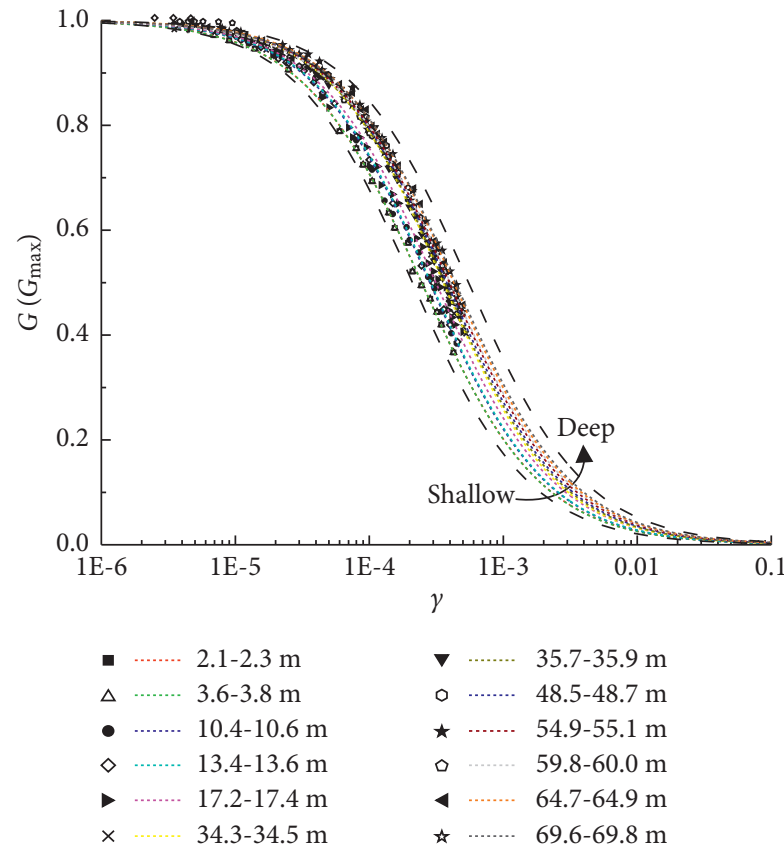

(a)

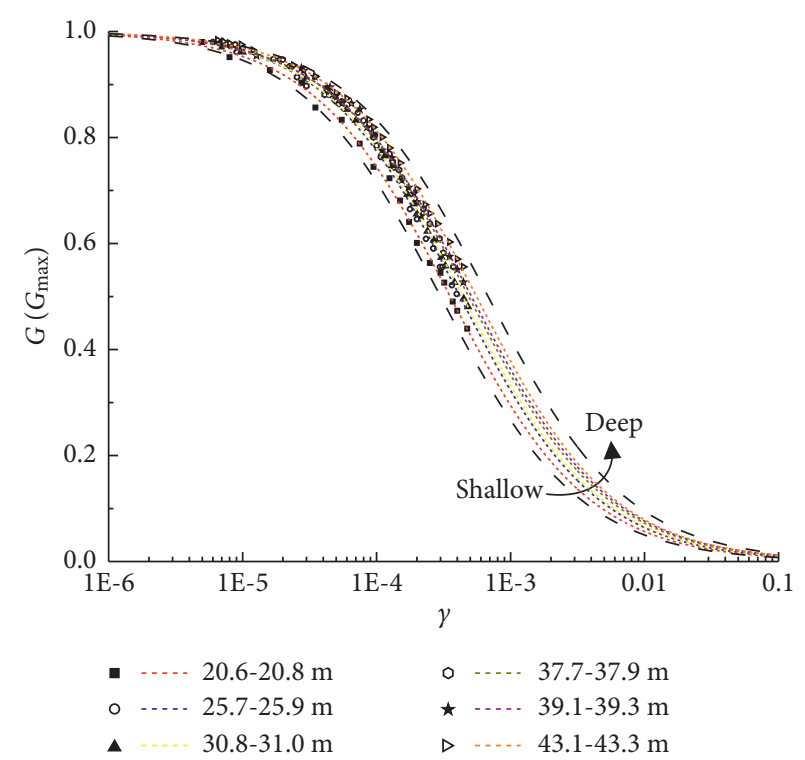

(b)

Figure 13: $G / G_{\max }-\gamma$ relationship curve of (a) silty clay and (b) silt at different depths.

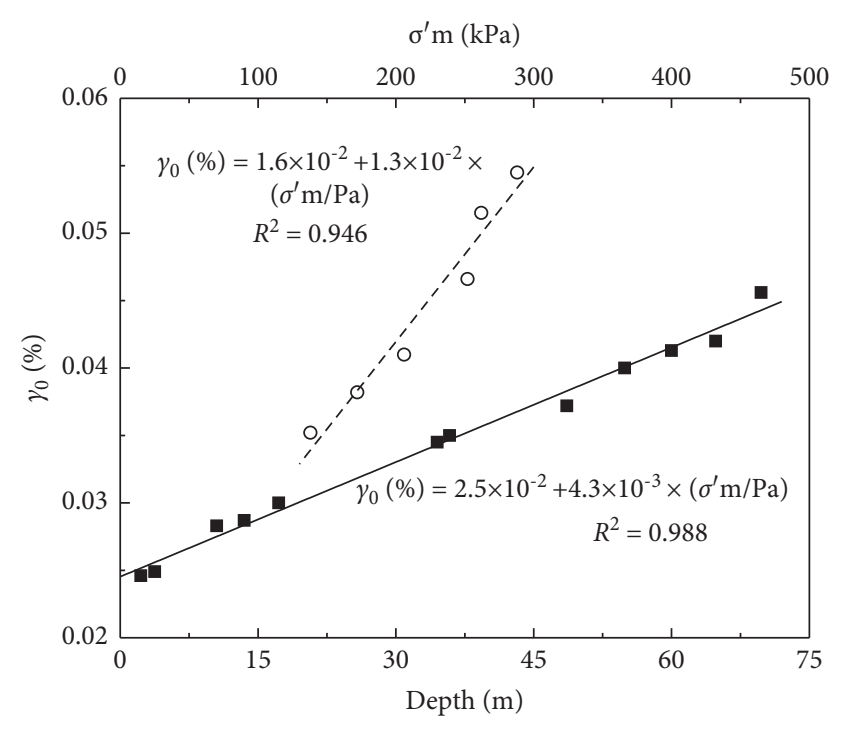

- Silty clay $\gamma_{0}$

○ Silt $\gamma_{0}$

Figure 14: Variation of $\gamma_{0}$ with soil depth $(H)$ (effective confining pressure $\sigma_{m}^{\prime}$ ) of silty clay and silt.

TABLE 3: Recommended values for parameters $\alpha, \beta$, and $\gamma_{0}$ in a simplified $G / G_{\max }$ regression model of silty clay and silt.

\begin{tabular}{lcccc}
\hline Lithology & $\alpha$ & $\beta$ & \multicolumn{2}{c}{$\gamma_{0}(\%)$} \\
& & & $B$ & $C$ \\
\hline Silty clay & 1 & 0.5 & $2.5 \times 10^{-2}$ & $4.3 \times 10^{-3}$ \\
Silt & 1 & 0.42 & $1.6 \times 10^{-2}$ & $1.3 \times 10^{-2}$ \\
\hline
\end{tabular}

3.8. Dynamic Shear Modulus Prediction Model Based on Soil Depth. An $H$-based $G$ prediction method can be established by combining equations (4), (6), and (7) to predict the $G$ values of primary soils at different depths and within different strain ranges. The specific equation is

$$
G=\frac{\left[A+n \times 0.1 P_{a} \times\left(\sigma_{m}^{\prime} / P_{a}\right)\right]}{\left[1+\left(\gamma / \gamma_{0}\right)^{2 \beta}\right]} .
$$

To investigate the performance of the above prediction method in predicting $G$ of the silty clay and silt at different depths within each strain range, the $G$ values of the silty clay and silt at different depths and different strain levels were back-calculated using Equation (8) and were compared with the existing test values. That is, given the soil depth and strain level, the level of correlation between $G_{\text {predict }}$ and $G_{\text {test }}$ was used to reflect the performance of the $G$ prediction method. Figure 15 shows the results of the $G$ prediction method for the silty clay and silt at different depths and different strain levels. The difference between the $G_{\text {predict }}$ and $G_{\text {test }}$ values of the silty clay and silt at different depths and different strain levels is basically within $10 \%$. This indicates that the proposed method can reasonably predict $G$ of the primary soils at different depths over the full strain range. In addition, the analysis shows that the standard deviations $\mu$ of equation (8) for the predicted values of the silty clay and silt soil $\left(G_{\text {predict }} / G_{\text {test }}\right)$ are 0.0511 and 0.019 , respectively. In addition, when the prediction error of $G_{\text {predict }} / G_{\text {test }}$ is required to be less than $5 \%$, the corresponding prediction accuracies are $75 \%$ and $96 \%$, respectively, which further verifies the validity of the prediction method and meets the reliability requirements of the probability analysis. 

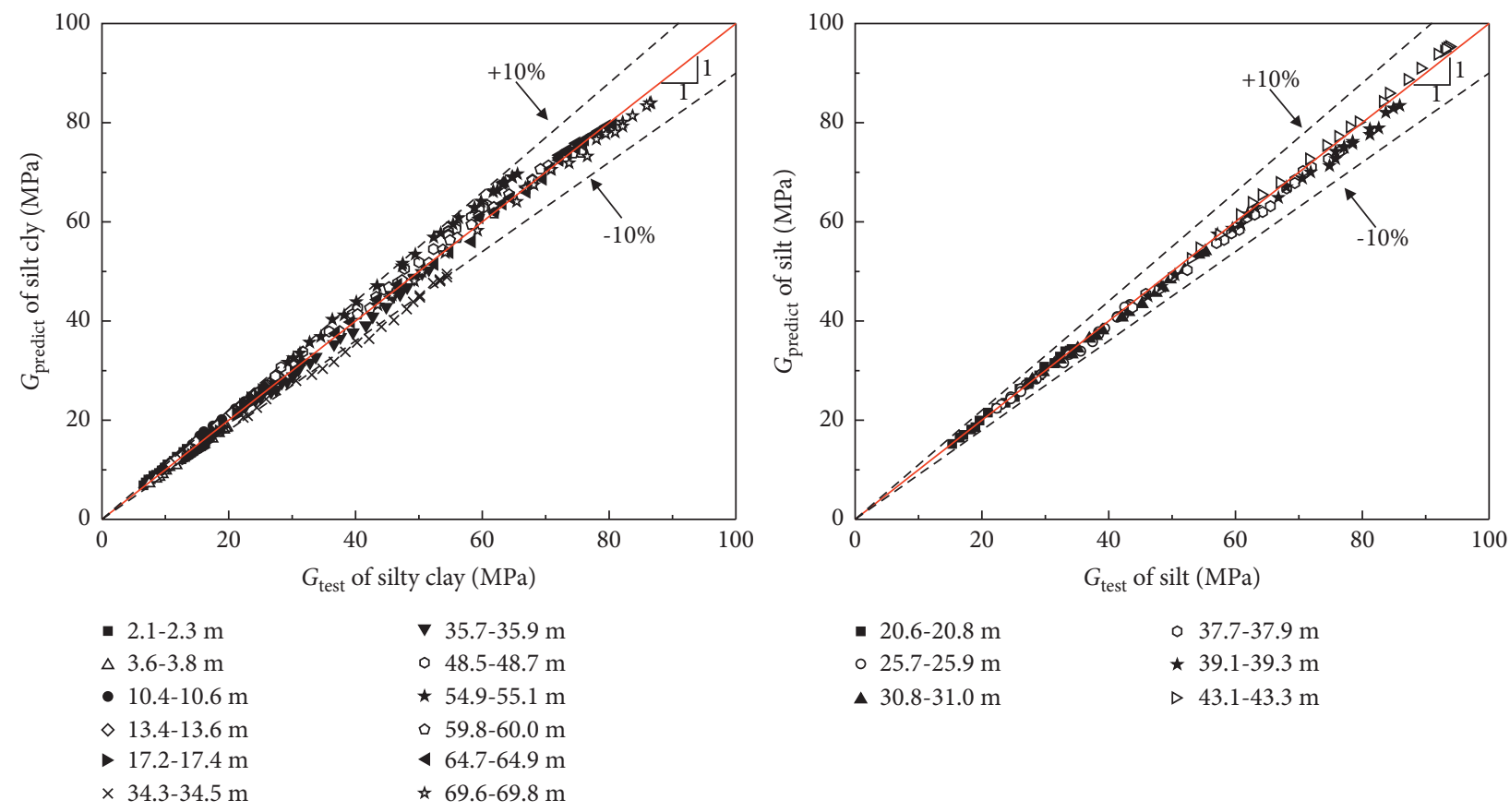

Figure 15: $G$ predicting effects of (a) silty clay and (b) silt within various strain ranges by an $(H)$-based $G$ prediction method.

\section{Conclusions}

In order to investigate the engineering mechanical properties of marine foundation soils of offshore wind power platforms, a series of basic physical index tests, including shear wave velocity test, undrained triaxial shear test, and resonance column test, were conducted on the disturbed and undisturbed seabed soils from the surface to the bedrock. The relationships between the basic physical indicators, the undrained shear strength, and shear wave velocity of the disturbed primary seabed soils were analyzed, a method for evaluating undrained shear strength was proposed, and the relationship between the dynamic shear modulus and the depth of the soil layer in the same type of undisturbed soil in each strain range was investigated. The conclusions and recommendations of this study are as follows:

(1) The silty clay layer and the silt layer within the depth range from the seabed surface to the bedrock each account for approximately half of the total drilling depth, and they are relatively discontinuously distributed. The upper layer has a high water content, and the water content of the lower layer is fairly constant at approximately $30 \%$. The specific gravity ranges from 2.66 to 2.70 with only a small variation. The silty clay has a plasticity index of greater than 10 , and the silt has a plasticity index of less than 10 .

(2) The $V_{s}$ values of the silt and silty clay both increase linearly with increasing the buried depth $H$. The effect of $H$ on $V_{s}$ of the seabed silt is significantly greater than that on $V_{s}$ of the silty clay. The $S_{d}$ values of the silty clay and silt decrease with increasing $e$, with both exhibiting a strong correlation. The rate of decrease of $S_{d}$ of the silty clay with increasing $e$ is significantly greater than that of the silty soil. The undrained shear properties of the silty clay are more sensitive to the soil density.

(3) The stress-strain relationship curves for the silty clay and silt both exhibit two types of development modes, i.e., strain hardening and strain softening. As $e$ decreases, the stress-strain relationship transits from strain hardening to strain-softening. However, the silt requires a higher density than the silty clay to undergo this stress-strain relationship transformation.

(4) Based on the relationship between $S_{d}$ and $V_{s}$ established using the results of the laboratory element tests conducted on the disturbed primary soil, a method for evaluating the undrained strength properties of an undisturbed primary soil under the current formation conditions was established based on the field shear wave velocity results and the existing methods for correcting the mechanical parameters of disturbed and undisturbed soils. However, this method may provide slightly conservative results for high-plasticity soils.

(5) $G$ of the undisturbed soil in each strain range is mainly determined by the soil type and $H . G_{\max }$ of undisturbed silty clay and silt increased linearly with increasing $H$, and the attenuation relationship of $G$ also decreased regularly with increasing $H$.

(6) In the Martin-Davidenkov model, $H$ has no significant effect on $\alpha$ and $\beta$ in the $G / G_{\max }$ fitting parameters of undisturbed soil. $\alpha$ of the undisturbed silty clay and silt soil at different depths are both close to 1 , and $\beta$ close to 0.5 and 0.42 , respectively. $\gamma_{0}$ shows a linear upward trend with increasing $H$. 
(7) The $G$ prediction method based on $H$ is established, and the accuracy is high, which can meet the needs in actual engineering applications.

\section{Data Availability}

The data used to support the findings of this study are available from the corresponding author upon request.

\section{Conflicts of Interest}

The authors declare that they have no conflicts of interest.

\section{Acknowledgments}

This work was supported by the research grant from the National Institute of Natural Hazards, Ministry of Emergency Management of China (no. ZDJ2017-28), and the National Key Research and Development Program of China (2017YFC1500403).

\section{References}

[1] D. C. Koutsoftas and J. A. Fischer, "Dynamic properties of two marine clays," Journal of the Geotechnical Engineering Division, vol. 106, no. 6, pp. 645-657, 1980.

[2] G. M. Bryan and R. D. Stoll, "The dynamic shear modulus of marine sediments," Journal of the Acoustical Society of America, vol. 83, no. 6, pp. 2159-2164, 1988.

[3] T. Yamamoto, M. V. Trevorrow, M. Badiey, and A. Turgut, "Determination of the seabed porosity and shear modulus profiles using a gravity wave inversion," Geophysical Journal International, vol. 98, no. 1, pp. 173-182, 1989.

[4] T. Kagawa, "Moduli and damping factors of soft marine clays," Journal of Geotechnical Engineering, vol. 118, no. 9, pp. 1360-1375, 1992.

[5] C. Vrettos and S. Savidis, "Shear modulus and damping for mediterranean sea clays of medium plasticity," Earthquake Geotechnical Engineering, vol. 12, no. 6, pp. 71-76, 1999.

[6] G. Lanzo, A. Pagliaroli, P. Tommasi, and F. L. Chiocci, "Simple shear testing of sensitive, very soft offshore clay for wide strain range," Canadian Geotechnical Journal, vol. 46, no. 11, pp. 1277-1288, 2009.

[7] L. W. Kong, H. B. Lv, R. Wang, and H. Shan, "Engineering properties and micro-mechanism of structural marine soil in Zhanjiang sea area," Journal of Hydraulic Engineering, vol. 33, no. 9, pp. 82-88, 2002.

[8] J. M. Zhang, H. X. Shan, and Y. G. Jia, "An experimental study of nonuniform consolidation of rapid sediment seabed soils at Yellow River mouth subjected to wave and tide wave loading," Rock and Soil Mechanics, vol. 7, pp. 88-94, 2007.

[9] H. J. Liu and H. J. Li, "A new suction anchor foundation of the yellow river delta offshore wind power," Periodical of Ocean University of China, vol. 44, no. 7, pp. 71-76, 2014.

[10] Q. Wu, Q. Lu, Q. Guo, K. Zhao, P. Chen, and G. Chen, "Experimental investigation on small-strain stiffness of marine silty sand," Journal of Marine Science and Engineering, vol. 8, no. 5, p. 360, 2020.

[11] K. Zhao, Q. Wang, S. Chen, H. Zhuang, and G. Chen, "Dynamic response of pipelines in liquefiable seabed under nature loadings: waves and currents," Ocean Engineering, vol. 230, no. 1, Article ID 109051, 2021.
[12] G. Zhang, P. Wang, M. Zhao, X. Du, and X. Zhao, "Seismic structure-water-sediment-rock interaction model and its application to immersed tunnel analysis under obliquely incident earthquake," Tunnelling and Underground Space Technology, vol. 109, no. 2, Article ID 103758, 2021.

[13] P. Wang, Y. Xu, X. Zhang, R. Xi, and X. Du, "A substructure method for seismic responses of offshore wind turbine considering nonlinear pile-soil dynamic interaction - ScienceDirect," Soil Dynamics and Earthquake Engineering, vol. 144, Article ID 106684, 2021.

[14] L. D. Bai, W. Xiang, A. S. Savidis, and F. Rackwitz, "Resonant column and bender element tests on maximum shear modulus of dry sand," Chinese Journal of Geotechnical Engineering, vol. 34, no. 1, pp. 184-188, 2012.

[15] J. Yang and X. Liu, "Shear wave velocity and stiffness of sand: the role of non-plastic fines," Géotechnique, vol. 66, no. 6, pp. 1-15, 2016.

[16] B. O. Hardin and V. P. Drnevich, "Shear modulus and damping in soils: design equations and curves," Journal of the Soil Mechanics and Foundations Division, vol. 98, no. 7, pp. 667-692, 1972.

[17] K. Zhao, Q. Wang, Q. Chen, H. Zhuang, and G. Chen, "Simplified effective stress simulation of shear wave propagation in saturated granular soils," Géotechnique Letters, vol. 11, no. 1, pp. 1-22, 2021.

[18] P. P. Martin and H. B. Seed, "One-dimensional dynamic ground response analyses," Journal of the Geotechnical Engineering Division, vol. 108, no. 7, pp. 935-952, 1982.

[19] M. B. Darendeli, Development of a New Family of Normalized Modulus Reduction and Material Damping Curves, The University of Texas, Austin, TX, USA, 2001. 